DOI: 10.12737/article_5a3cef5a94cab2.12952001

УДК 630. 165 (577.1)

МОЛЕКУЛЯРНО-ГЕНЕТИЧЕСКАЯ ДИФФЕРЕНЦИАЦИЯ ГЕНОТИПОВ БЕРЁЗЫ НА ОСНОВЕ ПОЛИМОРФИЗМА SSR-МАРКЕРОВ

\author{
доктор биологических наук Т.П. Федулова ${ }^{1}$ \\ доктор биологических наук Ю.Н. Исаков ${ }^{1}$ \\ кандидат биологических наук, доцент О.М. Корчагин ${ }^{1,2}$ \\ кандидат сельскохозяйственных наук, доцент И.Ю. Исаков ${ }^{2}$ \\ кандидат биологических наук А.М. Кондратьева ${ }^{1}$ \\ младший научный сотрудник С.Г. Ржевский ${ }^{1}$
}

1 - ФГБУ «Всероссийский научно-исследовательский институт лесной генетики, селекции и биотехнологии»

2 - ФГБОУ ВО «Воронежский государственный лесотехнический университет имени Г.Ф. Морозова»

В статье обсуждается использование микросателлитных (SSR) маркеров для оценки генетических ресурсов берёзы. Показано, что ДНК-анализ с помощью 12 микросателлитов наиболее подходит для внутривидовой дифференциации селекционно-ценных генотипов данной породы деревьев. Выявлен генетический полиморфизм у изученных генотипов берёзы по исследованным SSR локусам. Составлены мультилокусные генетические паспорта для 31 исследованного образца березы, позволившие на основе наличия (1) / отсутствия (0) 36 аллелей идентифицировать исследованные образцы.

Ключевые слова: береза, Betula, генотипирование, микросателлиты, SSR, полиморфизм, ПЦР, паспортизация.

\title{
MOLECULAR-GENETIC DIFFERENTIATION OF GENOTYPES OF BIRCH ON THE BASIS OF SSR- MARKERS POLYMORPHISM
}

\author{
DSc (Biology) T.P. Fedulova ${ }^{1}$, \\ DSc (Biology) Y.N. Isakov ${ }^{1}$ \\ $\mathrm{PhD}$ (Biology), Associate Professor O.M. Korchagin ${ }^{1,2}$ \\ $\mathrm{PhD}$ (Agriculture), Associate Professor I. Y. Isakov ${ }^{2}$ \\ $\mathrm{PhD}$ (Biology) A.M. Kondratyeva ${ }^{1}$ \\ Junior Reseacher S.G. Rzhevskiy ${ }^{1}$ \\ 1 - FSBI «All-Russian Research Institute of Forest Genetics, Breeding and Biotechnology» \\ 2 - FSBEI HE «Voronezh State University of Forestry and Technologies named after G.F. Morozov»
}

\begin{abstract}
The article discusses the use of microsatellite (SSR) markers for the estimation of genetic resources of birch. It is shown that DNA analysis using 12 microsatellites is most suitable for intraspecific differentiation of selectively valuable genotypes of this tree species. The genetic polymorphism in the studied birch genotypes was determined from the loci examined by SSR. Multilocus genetic passports were prepared for 31 samples of birch, which allowed (based on the presence (1) / absence (0) of 36 alleles) to identify the investigated samples.
\end{abstract}

Keywords: birch, Betula, genotyping, microsatellites, SSR, polymorphism, PCR, passportization. 
Введение. В настоящее время методы молекулярной генетики всё шире применяются в лесном хозяйстве для оценки и мониторинга состояния лесных генетических ресурсов, управления процессами лесовосстановления, фитосанитарного мониторинга лесных насаждений и питомников, получения селекционного посадочного материала. Одной из основных задач лесного хозяйства является лесовосстановление и лесоразведение. Быстрое и качественное лесовосстановление возможно только при выполнении ряда условий, таких как использование на плантациях улучшенного посадочного материала и его надежная идентификация, в том числе и с применением молекулярно-генетических методов.

При изучении генетического популяционного разнообразия всё чаще применяется микросателлитный метод (SSR) [1, 2], основанный на подборе эффективных маркеров, дающих большое число хорошо воспроизводимых ДНК-ампликонов. В настоящее время для исследования внутри- и межвидовой изменчивости данный метод считается наиболее информативным.

Целью исследования являлось выявление генетического полиморфизма и составление генетических паспортов селекционно-ценных образцов березы.

Обзор литературы. Микросателлитные маркеры широко применяются с целью изучения автополиплоидии и генетической структуры популяций различных видов берез [3-8]. Для вида Betula pendula разработана структура 23 пар праймеров, комплементарных микросателлитным локусам (L1.10, L2.2, L2.3, L2.7, L3.1, L3.3, L3.4, L4.4, L5.1, L5.4, L5.5, L7.1a, L7.3, L7.4, L7.8, L10.1, L11.1, L13.1, L021, L012, L022, L63, L52), с количеством аллелей на выходе ПЦР от 2 до 20 [9]. Из них 2 пары праймеров (для L5.4, L7.1a) были протестированы при амплификации у некоторых других видов березы (B. pubescens ssp. pubescens, B. pubescens ssp. czerepanovii, B. nana, B. fruticosa, B. maximowicziana, B. alleghaniensis) и ольхи серой (Alnus incana). При использовании разработанной пары праймеров для L5.4 амплификация прошла успешно у всех перечисленных видов березы и ольхи, а для L7.1a ПЦР- продуктов не отметилось только у ольхи серой. Разработанные пары праймеров для локусов L1.10 и L3.1 опробованы на B. pubescens ssp. pubescens, B. pubescens ssp. czerepanovii и B. nana.

Для подвида березы пушистой $B$. pubescens ssp. tortuosa из трех популяционных линий разработаны и протестированы 9 пар праймеров, комплементарных микросателлитным высокополиморфным локусам (L2.3, L2.5, L3.1, L1.10, L5.4, L021, Bo.F394, Bo.F330, Bo.G182), дающим 14-42 аллеля [10].

Для вида $B$. alnoides исследовано 19 микросателлитных маркеров серии BAG [11] с 3-12 аллелями. 17 из разработанных для них пар праймеров были успешно амплифицированы у B. luminifera, 13 - у B. fujianensis.

Проведен обзор данных обо всех имеющихся в GenBank последовательностях микросателлитных маркеров березы [12]. Исследована возможность использования 52 микросателлитных пар праймеров березы для гибридизации в других родах семейства Betulaceae, при этом эффективность амплификации составила $92,3 \%$ для рода Betula, 50,6\% - Alnus, 41,2\% - Corylus, 36,5\%-Carpinus, $34,0 \%$ - Ostrya и 34,6 \% - Ostryopsis [12, 13]. Микросателлиты применяются также при изучении происхождения и эволюционной истории берез [14-16].

Развитие молекулярно-генетических методов открыло новые методические возможности для изучения особенностей динамики популяционногенетической структуры различных видов растений, в том числе и таких, как береза повислая и пушистая. Получаемая таким образом информация необходима при разработке стратегии сохранения генофонда и рационального использования ресурсов. На основании изложенного выше применение SSR-маркеров при исследовании генетического разнообразия популяций березы и для выявления возможных генетически детерминированных причин сокращения ее численности и деградации генофонда является актуальным направлением исследований [5].

\section{Материалы и методы исследований}

Для генетической оценки доктором биол. наук Ю.Н. Исаковым и канд. с.-х. наук И.Ю. Исаковым 


\section{Естественные науки и лес}

отобран 31 образец селекционного ценного материала берёз в возрасте 33 лет, произрастающих в Воронежском государственном биосферном заповеднике, квартал 298 (табл. 1). Материал представлен вторым поколением, полученным при свободном опылении деревьев первого поколения (гибридов местных берёз - пушистой Betula pubescens Ehrh. и повислой Betula pendula Roth., а также потомства от свободного опыления). Наличие в тканях вегетирующих растений ингибиторов ПЦР усложняет очистку нуклеиновых кислот. По этой причине экстракция ДНК осуществлялась из только что распустившихся листьев модифицированным нами ЦТАБ-методом. Использованный метод делает возможным получение нуклеиновых кислот доста- точно высокой степени чистоты, что позволяет на выходе ПЦР дать ампликоны, хорошо визуализируемые на электрофорезе [17]. К тому же использованный метод ниже по себестоимости по сравнению с готовыми коммерческими наборами. Для разрушения мембран растительных клеток ткани растирались пестиком в ступке с подогретым $2 \%$ ЦТАБ-буфером (2 \% СТАВ, 1,5 M NaCl, 100 mM Tris-base, 50 mM EDTA; pH 8.0). Клеточный гомогенат инкубировался 30 минут при $65{ }^{\circ} \mathrm{C}$ в термостате, пробирки периодически встряхивали. Затем, охладив пробирки, добавляли равный объем смеси хлороформ : изоамиловый спирт $(24: 1)$ и перемешивали содержимое.

Таблица 1

Характеристика образцов березы, отобранных для молекулярно-генетического анализа

\begin{tabular}{|c|c|c|c|}
\hline № образца & Инв. № & № бирки & Вид / гибрид \\
\hline 1 & 2 (прививка) & Y041730 & B. pendula $\times$ B. pubescens \\
\hline 2 & 6 & Y041726 & B. pendula $\times$ B. pubescens \\
\hline 3 & $13 / 7$ & У041729 & B. pendula $\times$ B. pubescens \\
\hline 4 & 13 & K281816 & B. pendula \\
\hline 5 & $33 / 28($ Б-12 c/o) & K281818 & B. pubescens \\
\hline 6 & $34 / 5($ Б-12 св/o) & K281819 & B. pubescens \\
\hline 7 & $38 / 22($ Б-18 c/o) & K181820 & B. pubescens \\
\hline 8 & $37 / 24($ Б-11 c/o) & K281814 & B. pubescens \\
\hline 9 & C 5 & K281828 & B. pendula $\times$ Betula pendula var. carelica \\
\hline 10 & $\mathrm{p} /$ /л-4 & У041716 & Betula \\
\hline 11 & ШТ-1 & Y041702 & Betula pendula var. carelica \\
\hline 12 & ШТ-2 & K191424 & Betula pendula var. carelica \\
\hline 13 & ШТ-3 & K191422 & Betula pendula var. carelica \\
\hline 14 & ШТ-4 & Y041703 & Betula pendula var. carelica \\
\hline 15 & $6 / \Pi-2$ & У041704 & Betula pendula var. carelica \\
\hline 16 & б/ח-1 & Y041707 & Betula pendula var. carelica \\
\hline 17 & карлик & Y041713 & Betula pendula var. carelica \\
\hline 18 & $3 / 13$ (п/к) & У041720 & Betula pendula var. carelica \\
\hline 19 & $3 / 22$ (б/п) & Y041712 & Betula pendula var. carelica \\
\hline 20 & $\sigma / \Pi$ & Y041721 & Betula pendula var. carelica \\
\hline 21 & п/к-2 p & Y041714 & Betula pendula var. carelica \\
\hline 22 & кустов. No.310 & K191417 & Betula pendula var. carelica \\
\hline 23 & $\Pi / \kappa-3$ & K191430 & Betula pendula var. carelica \\
\hline 24 & кап-5 & K191419 & B. pubescens (свободное опьление) \\
\hline 25 & $8 / 31(\mathrm{C}-30 \mathrm{c} / \mathrm{o})$ & K191428 & B. pendula \\
\hline 26 & $8 / 21(\mathrm{C}-30 \mathrm{c} / \mathrm{o})$ & K191427 & B. pendula \\
\hline 27 & $8 / 1(\mathrm{C}-30 \mathrm{cв} / \mathrm{o})$ & K191420 & B. pendula \\
\hline 28 & $8 / 2(\mathrm{C}-30$ св/o) & K191425 & B. pendula \\
\hline 29 & $3 / 33(\mathrm{C}-31 \mathrm{c} / \mathrm{o})$ & K191426 & B. pendula \\
\hline 30 & $3 / 4(\mathrm{C}-31 \mathrm{cB} / \mathrm{o})$ & K191429 & B. pendula \\
\hline 31 & $34 / 10($ Б-12 св/о) & K191418 & B. pubescens \\
\hline
\end{tabular}




\section{Естественные науки и лес}

После центрифугирования в течение 15 минут (14 000 об/мин, комнатная температура) к отобранному супернатанту добавляли половину объема хлороформа, проводили центрифугирование ещё раз. Полученный супернатант отбирали в новые пробирки и для осаждения ДНК добавляли двойной объем 96 \% этилового спирта. Пробирки инкубировали 30 минут в морозильной камере $\left(-20^{\circ} \mathrm{C}\right)$, после чего их центрифугировали 30 минут (14 000 об/мин при $\left.4{ }^{\circ} \mathrm{C}\right)$. Отбирали жидкость, промывали осадок $70 \%$ этанолом, подсушивали и растворяли в TE-буфере (10 mM Tris, 1 mM EDTA; pH 8.0). Для визуализации полученного препарата ДНК и определения степени его деградации проводили электрофорез в $0,7 \%$ агарозном геле с добавлением этидия бромида. Полученный тотальный препарат ДНК хранили при $-20{ }^{\circ} \mathrm{C}$ и использовали для проведения ПЦР. В процессе исследований нами подобрано и протестировано по 12 специфических микросателлитных локусов для видов рода Betula $[9,10]$ (табл. 2). Для праймеров каждого локуса оптимизировали температуры отжига. Подобранные температуры отжига для микросателлитных праймеров для березы приведены в табл. 3, 4. Оптимизирован режим амплификации для берёзы: 3 минуты - предварительная денатурация при $94{ }^{\circ} \mathrm{C}$; затем 35 циклов: 30 секунд - денатурация при $94{ }^{\circ} \mathrm{C}, 40$ секунд - отжиг, $15-25$ секунд - элонгация при $72{ }^{\circ} \mathrm{C} ; 5$ минут - окончательная элонгация при $72{ }^{\circ} \mathrm{C}$. Также нами оптимизирован состав реакционной ПЦР-смеси (объем 20 мкл) следующего состава: 10 х ПЦР-буфер (2 мкл), смесь четырех dNTP, 2 mM (2 мкл), смесь двух праймеров, $2 \mu \mathrm{M}$ (4 мкл), ДНК-матрица 1 мкл, Таq-полимераза 5 ед./мкл (0,3 мкл), вода 11 мкл.

Продукты ПЦР разделяли методом электрофореза в $3 \%$ агарозном геле в горизонтальной камере Power Pac TM Universal («BIO-RAD», CША) в течение 3 часов при напряжении электрического поля 60 В. Применялся однократный ТВЕ-буфер (89mM Tris, $89 \mathrm{mM} \mathrm{H}_{3} \mathrm{BO}_{3}, 2 \mathrm{mM}$ EDTA; $\mathrm{pH}$ 8.0). Окрашивание осуществлялось бромидом этидия.

Таблица 2

Характеристика микросателлитных локусов березы

\begin{tabular}{|c|c|c|c|c|c|c|c|}
\hline $\begin{array}{l}\text { № } \\
\text { п/п }\end{array}$ & Локус & $\begin{array}{l}\text { Инв. } \\
\text { номер }\end{array}$ & $\begin{array}{l}\text { Последовательность } \\
\text { праймера (5' - 3') }\end{array}$ & Повтор & $\begin{array}{l}\text { Т от- } \\
\text { жига, } \\
{ }^{\circ} \mathrm{C}\end{array}$ & $\begin{array}{l}\text { Число } \\
\text { выявлен- } \\
\text { ных алле- } \\
\text { лей }\end{array}$ & $\begin{array}{l}\text { Размер ПЦР- } \\
\text { продукта }\end{array}$ \\
\hline 1 & L1.10 & AF310856 & $\begin{array}{l}\text { ACGCTTTCTTGATGTCAGCCTCACCAAGTTC } \\
\text { CTGGTGGAT }\end{array}$ & $\begin{array}{l}(\mathrm{AG})_{4} \mathrm{AA} \\
(\mathrm{AG})_{10}\end{array}$ & 55 & 4 & $160-200$ \\
\hline 2 & L2.3 & AF310847 & $\begin{array}{l}\text { CAGTGTTTGGACGGTGAGAACGGGTGAAGT } \\
\text { AGACGGAACT }\end{array}$ & $(\mathrm{AG})_{16}$ & 55 & 3 & $190-220$ \\
\hline 3 & L3.1 & AF310851 & $\begin{array}{l}\text { CTCCTTAGCTGGCACGGACCCCTTCTTCATA } \\
\text { AAACCCTCAA }\end{array}$ & $\begin{array}{l}(\mathrm{CT})_{3} \mathrm{CC} \\
(\mathrm{CT})_{2} \mathrm{CC} \\
(\mathrm{CT})_{13} \mathrm{AT} \\
(\mathrm{CT})_{5}\end{array}$ & 59 & 4 & $210-250$ \\
\hline 4 & L3.4 & AF310852 & $\begin{array}{l}\text { AACCCTCGTTTGGCTACTGAGAACAGTTACT } \\
\text { AGTCAAACTGAAAACC }\end{array}$ & $\begin{array}{l}(\text { GTAT })_{3} \\
(\text { GT })_{5}\end{array}$ & 55 & 2 & $250-270$ \\
\hline 5 & L4.4 & AF310858 & $\begin{array}{c}\text { TTGAGATAGACGATAGAGGTAAAGCAAGGC } \\
\text { ATTTCTCCAATTTTCTT }\end{array}$ & $(\mathrm{AG})_{17}$ & 55 & 3 & $250-280$ \\
\hline 6 & L5.4 & AF310862 & $\begin{array}{l}\text { AAGGGCACCTGCAGATTAGAAAAATTGCAA } \\
\text { CAAAACGTGC }\end{array}$ & $(\mathrm{TC})_{26}$ & 55 & 4 & $240-270$ \\
\hline 7 & L7.1a & AF310854 & $\begin{array}{l}\text { GTTTTGGGTTTCCACTTCCAACTGGTAATACC } \\
\text { TTTACCAAGCC }\end{array}$ & $\begin{array}{l}(\mathrm{CT})_{12} \mathrm{CCT} \\
\mathrm{T}(\mathrm{CT})_{4}\end{array}$ & 55 & 1 & 150 \\
\hline 8 & L7.3 & AF310864 & $\begin{array}{c}\text { GGGGATCCAGTAAGCGGTATCACACGAGAG } \\
\text { ATAGAGTAACGGAA }\end{array}$ & $(\mathrm{GT})_{18}(\mathrm{GA})$ & 55 & 4 & $190-230$ \\
\hline 9 & L7.4 & AF310855 & $\begin{array}{l}\text { TGAAACGAACGGAAGAGTTGATACGCCAGA } \\
\text { CTTTCATCCG }\end{array}$ & $(\mathrm{GA})_{7}$ & 59 & 2 & $240-250$ \\
\hline 10 & L13.1 & AF310871 & $\begin{array}{l}\text { CACCACCACAACCACCATTAAACACCCTTTG } \\
\text { CAACAATGA }\end{array}$ & $(\mathrm{CA})_{3}(\mathrm{GA})_{1}$ & 55 & 4 & $80-120$ \\
\hline 11 & L021 & AF310877 & $\begin{array}{l}\text { GCCAAAGCCAACGCTAGTAATCCTAGCCGA } \\
\text { GAGAAGTTGC }\end{array}$ & $(\mathrm{CT})_{13}$ & 59 & 1 & 190 \\
\hline 12 & $\begin{array}{l}\text { Bo.F39 } \\
4\end{array}$ & AY423608 & $\begin{array}{l}\text { AATGCAGCATCTCTTACCCACGCAATAATAT } \\
\text { GGAAA }\end{array}$ & $(\mathrm{TC})_{13}$ & 48 & 4 & $130-160$ \\
\hline
\end{tabular}




\section{Естественные науки и лес}

Визуализация полученных ампликонов проводилась на трансиллюминаторе TFP («Vilber Lourmat», Франция). Размер полученных фрагментов определялся по сравнению с ДНК-маркерами 100 bp Ladder DNA marker (100 bp - 3000 bp) («Axygen», США) и М34 (100 bp + 50 bp) («СибЭнзим», Россия). Результаты анализа были воспроизведены на всех этапах в трёхкратной повторности.

С выделенными и очищенными ДНК исследованных генотипов березы проводился ПЦРанализ в соответствии с программами, оптимизированными для каждой пары использованных праймеров. Результат амплификации по каждому из микросателлитных локусов приводится в виде электрофореграмм. По результатам проведенного ПЦР-анализа генотипов березы пушистой и повислой и их гибридов по 12-и SSR-маркерам $100 \%$-м полиморфизмом и наибольшим числом выявленных аллелей характеризуются локусы L1.10, L3.1, L7.3, L13.1, L5.4, Bo.F394.
Результаты исследований и обсуждение

В локусе L1.10 обнаружено 4 ДНК-ампликона, размах варьирования длин составляет от 160 п. н. до 200 п. н. (рис. 1). Аллель 160 п. н. отмечен только у четырех образцов (No.10, 13, 14, 27). Обозначения номеров согласно табл. 2. В локусе L3.1 насчитывается 4 ПЦР-продукта с варьированием длин от 210 п. н. до 250 п. н. (рис. 2). Аллель 250 п. н. присутствует только у образца No.14, а аллель 230 п. н. отсутствует только у образцов No.4 и No.8. Данный микросателлитный маркер показал возможность установления полиплоидности (наличие трех аллелей 210, 230, 240 п. н. у образцов No.3 и No.7). Микросателлитный маркер Bo.F394 по результатам анализа характеризуется четырьмя ДНКфрагментами (130-160 п. н.) (рис. 3). В локусе L7.3 (рис. 4) размер четырех наблюдаемых фрагментов изменяется в пределах от 190 п. н. до 230 п. н. Фрагмент размером 190 п. н. присутствует у образцов No.26, 29, фрагмент 220 п. н. - No.7-9. Аллель 200 п. н. отмечен у всех исследованных образцов, кроме No.4, 8, 9.

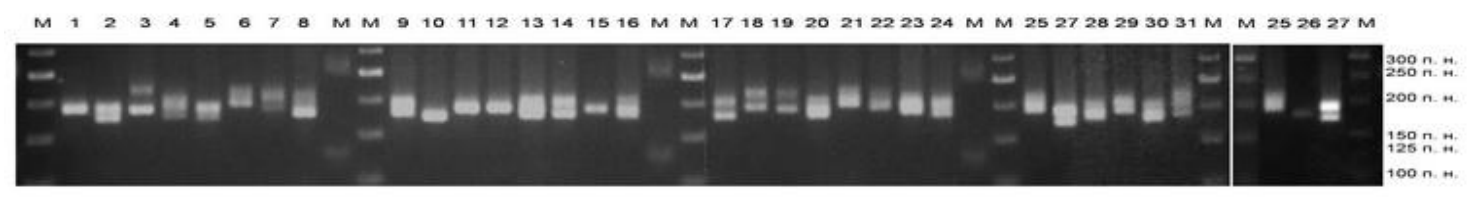

Рис. 1. Электрофореграмма продуктов ПЦР образцов березы (1-31) по локусу L1.10 (М - маркер молекулярных масс)

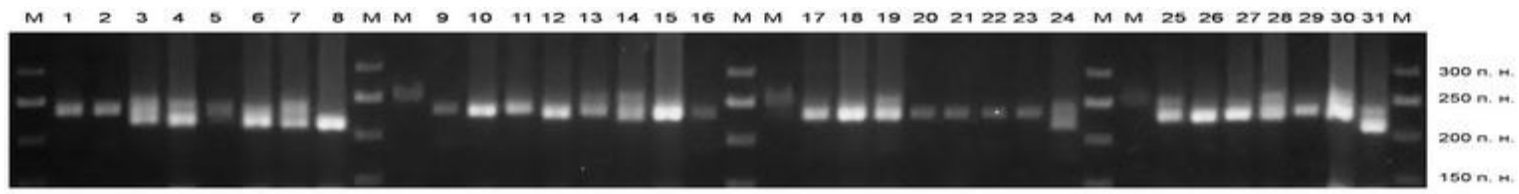

Рис. 2. Электрофореграмма продуктов ПЦР образцов березы (1-31) по локусу L3.1 (М - маркер молекулярных масс)

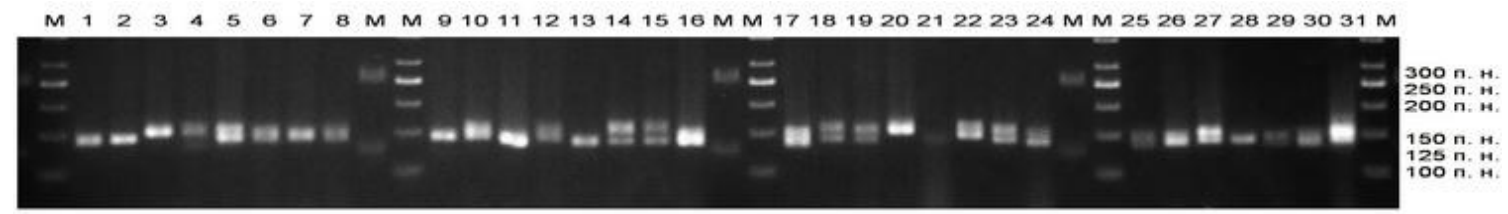

Рис. 3. Электрофореграмма продуктов ПЦР образцов березы (1-31) по локусу Bo.F394 (М - маркер молекулярных масс)

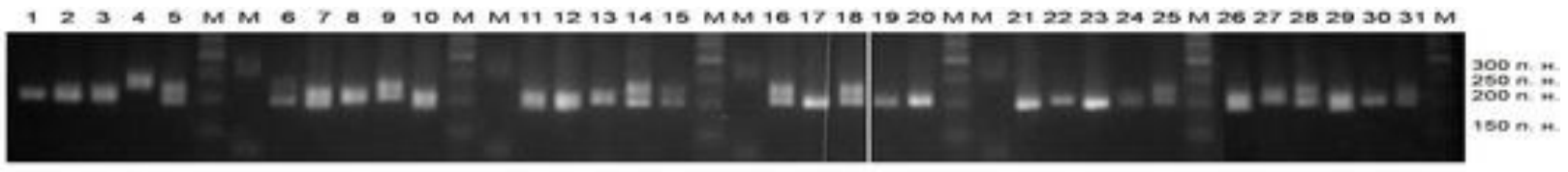

Рис. 4. Электрофореграмма продуктов ПЦР образцов березы (1-31) по локусу L7.3 (М - маркер молекулярных масс) 


\section{Естественные науки и лес}

Локус L13.1 характеризуется четырьмя аллелями (80-120 п. н.) (рис. 5). Фрагмент 80 п. н. присутствует только у образцов No.4, 6, 8, 24, 31; 120 п. н. - только у No.1, 3, 12, 13, 15. Локус L5.4 характеризуется четырьмя аллелями (240-270 п. н.) (рис. 6). Фрагмент 240 п. н. отмечен почти у всех исследованных образцов, кроме No.1, 4, 14, 27. Аллель 260 п. н. присутствует только у образцов No.5, $6,8,9,11 ; 270$ п. н. - только у No.13, 28, 30. Перечисленные ядерные микросателлиты в наибольшей степени подходят для идентификации и паспортизации образцов березы.

Локус L2.3 характеризуется тремя аллелями (190-220 п. н.). Аллель 210 п. н. присутствует только у образцов No.1, 18-20, 23.

С использованием праймеров к локусу L4.4 ампликон 260 п. н. отмечен почти у всех исследованных образцов, кроме No.10, 19, 22, 24, 28. Аллель 250 п. н. присутствует только у образцов No.19, 20, 22-24, 28; 280 п. н. - только у No.7, 10, 31. Наименьшее количество аллелей (по 2 ДНКфрагмента) установлено по L3.4, L7.4. В локусе L3.4 отмечено только два ампликона, 250 п. н. до 270 п. н. Уровень полиморфизма - 100 \%. Микросателлит L7.4 характеризуется двумя аллелями 240 и 250 п. н. При этом аллель 240 п. н. отмечен у образцов No.4, 13, 17, а аллель 250 п. н. присутствует у всех образцов (уровень полиморфизма - 50 \%). Не полиморфными и, следовательно, не информативными для исследуемых гибридов и форм берез оказались локусы L7.1a и L021, представленные одним ПЦР-продуктом (150 и 190 п. н. соответственно). Следовательно, данные праймеры не могут быть использованы для генетической дифференциации генотипов берёзы. Среди исследованных генотипов берез всего детектировано 439 SSRфрагментов, из которых 346 оказались полиморфными, что составляет 78,8 \% ампликонов. Длина полученных продуктов варьируется от 80 до 280 п. н. Среднее число ДНК-фрагментов на локус - 36,6, максимальное - 47 (Bo.F394), минимальное - 31 (L7.1a, L021). Среднее число полиморфных ампликонов на локус - 28,8, максимальное - 47 (Во.F394), минимальное - 3 (L7.4). По результатам проделанной работы выделен 31 уникальный генотип березы (из 31 исследованного образца). Для части проанализированных образцов установлены микросателлиты с уникальным аллельным составом: локус L3.1 - для образцов No.4, 8 и 14; Bo.F394 - No.13, 16, 17, 20; L7.3 - No.4, 7, 8 и 9; L2.3 - No.19 и 23; L3.1 - No.15. Для генотипа No.10 выявлено сразу два маркера со специфичным набором аллелей (L1.10 и L4.4). Генотипы No.3 и No.7 существенно отличаются от других исследованных образцов наличием в локусе L3.1 трех аллелей, а между собой - по остальным локусам. Образцы №.11, 29, 30 выделяются по набору фрагментов L13.1, а между собой - по L5.4; No.22, 25, 26, 31 от других - по L5.4, между собой - по L1.10 и L13.1. Ряд исследованных генотипов возможно идентифицировать только по комбинации аллелей в двух микросателлитах: образцы No.2 и 24 - по локусам L1.10 и L2.3; No.21 - L1.10 и L4.4; No.27 - L1.10 и Bo.F394; No. 5 - L5.4 и L7.3; No.6 - L3.1 и L5.4; No. 1 - L13.1 и L3.1; No.12 - L13.1 и Bo.F394;No.18 - L2.3 и L7.3. Образец N.28 отличается от остальных только по комбинации сразу трех локусов (L4.4, L3.1, L5.4). Пример аллельного состава и шифры микросателлитных локусов исследованных генотипов берёзы представлены в табл. 3 .

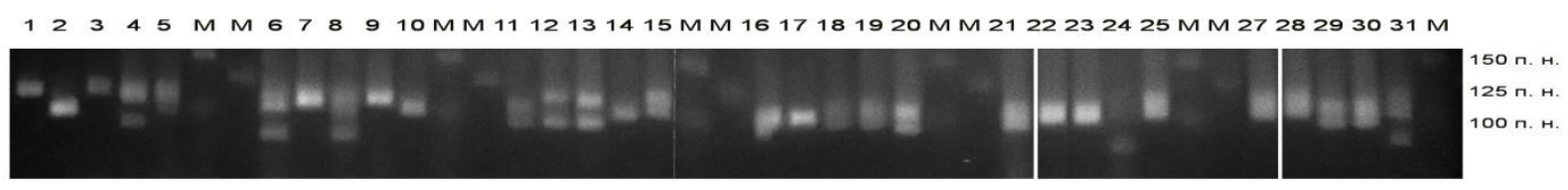

Рис. 5. Электрофореграмма продуктов ПЦР образцов березы (1-31) по локусу L13.1 (M - маркер молекулярных масс)

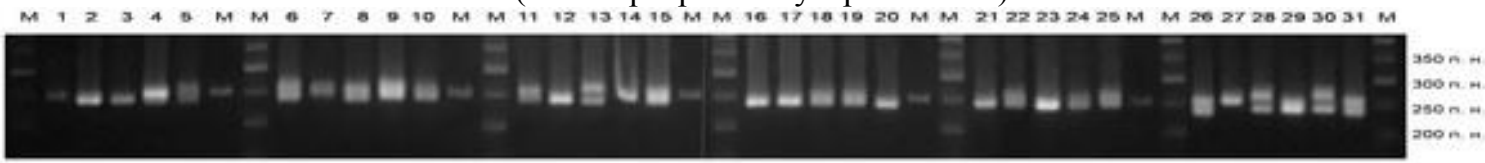

Рис. 6. Электрофореграмма продуктов ПЦР образцов березы (1-31) по локусу L5.4 (М - маркер молекулярных масс) 
Аллельный состав микросателлитных локусов исследованных генотипов березы (п. н.)

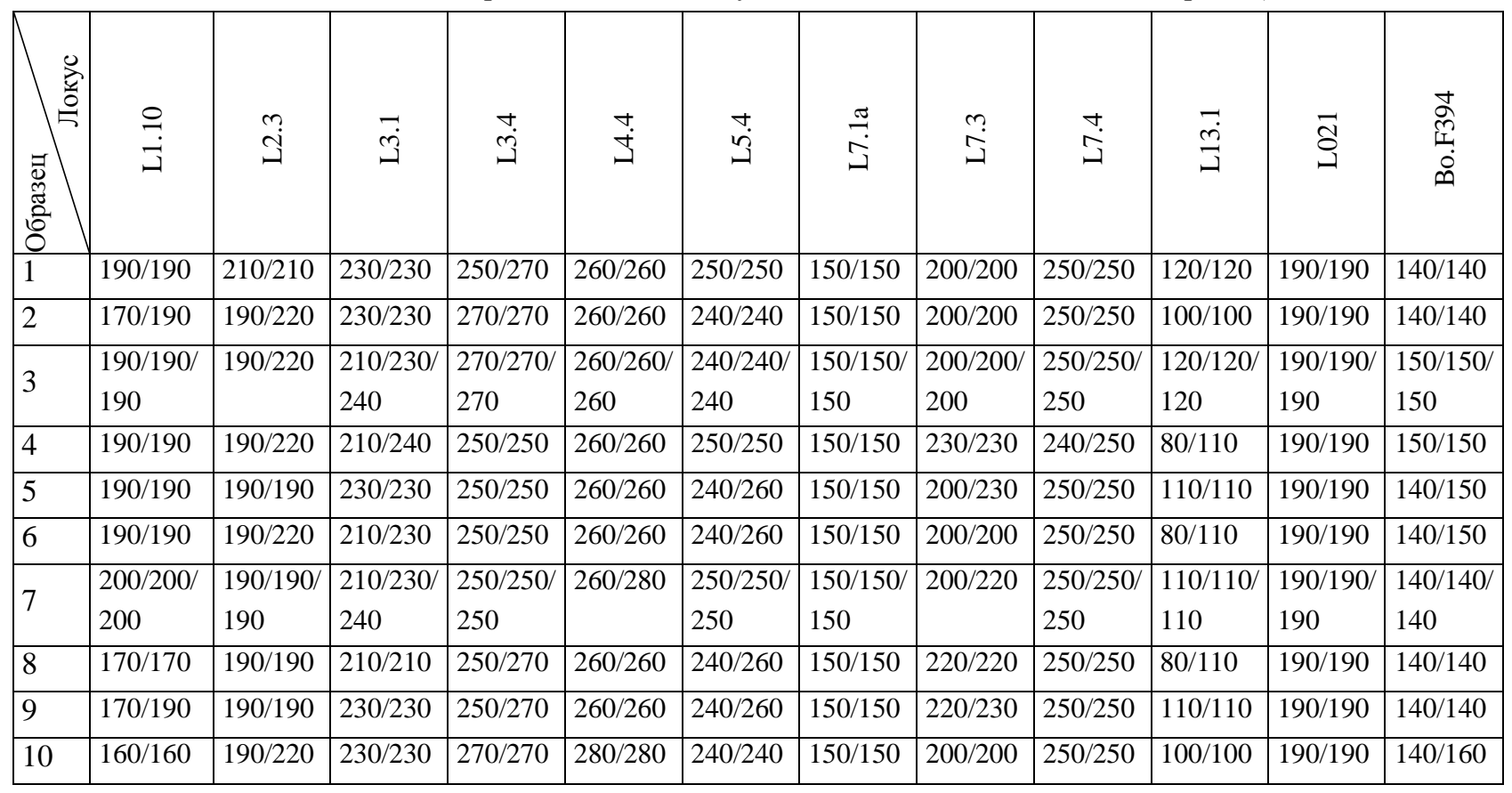

По 12 исследованным SSR-маркерам составлены мультилокусные паспорта генотипов березы (табл. 3), позволяющие на основе наличия (1) / отсутствия (0) 36 аллелей идентифицировать исследованные образцы. По результатам проведенного молекулярного анализа установлено, что образцы берёзы повислой (Betula pendula Roth.) отличаются от берёзы пушистой (Betula pubescens Ehrh.) по локусам L. 3.1, L.7.3, L.1.10, L.4.4, L.5.4, L13.1 наличием или отсутствием выявленных ДНК-ампликонов. От берёзы карельской (Betula pendula var. carelica) берёза повислая и пушистая различаются по локусам L.2.3, L.7.3, L.1.10, L.4.4, L.5.4.

Заключение. Таким образом, в результате проведенной работы показана возможность диагностирования индивидуальных генотипов березы на основе полиморфизма микросателлитных маркеров. Составлены мультилокусные генетические паспорта для 31 исследованного образца березы, которые позволяют проводить идентификацию и паспортизацию генотипов данного объекта. Из анализа полученных данных следует, что для проведения молекулярно-генетической паспортизации и идентификации ценных для селекции генотипов березы предлагается применять микросателлитные локусы: L1.10, L2.3, L3.1, L3.4, L4.4, L5.4, L7.3, L7.4, L13.1 и Bo.F394 (уровень полиморфизма локусов составляет 50-100 \%).

На первых этапах для анализа генетического разнообразия берёз необходимо использовать ядерные микросателлитные маркеры. Они имеют двуродительское наследование, в геномах берёзы многочисленны, кодоминантны, вариабельны и распространены во всех частях генома. Также микросателлитные маркеры позволяют выявлять самый высокий уровень гетерозиготности.

Примечание авторов: полные мультилокусные генетические паспорта всех исследованных генотипов берёзы, полные шифры локусов и электрофореграммы могут быть предоставлены авторами по запросу. 
Таблица 4

Мультилокусные генетические паспорта исследованных генотипов березы (пример)

\begin{tabular}{|c|c|c|c|c|c|c|c|c|c|c|c|c|c|c|c|c|c|c|c|c|}
\hline \multirow[b]{2}{*}{ 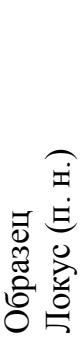 } & \multicolumn{4}{|c|}{$\mathrm{L} 1.10$} & \multicolumn{3}{|c|}{ L2.3 } & \multicolumn{4}{|c|}{ L3.1 } & \multicolumn{2}{|c|}{ L3.4 } & \multicolumn{3}{|c|}{ L4.4 } & \multicolumn{4}{|c|}{ L5.4 } \\
\hline & $\stackrel{8}{0}$ & $\stackrel{2}{1}$ & 잉 & ¿ి & @ & $\stackrel{0}{\sim}$ & तิ & $\stackrel{0}{\sim}$ & ঠి & 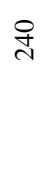 & $\stackrel{\circ}{\sim}$ & 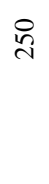 & $\stackrel{尺}{\curvearrowright}$ & $\stackrel{\circ}{i}$ & 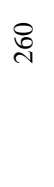 & 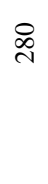 & 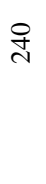 & 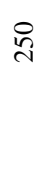 & : & 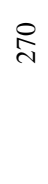 \\
\hline 1 & 0 & 0 & 1 & 0 & 0 & 1 & 0 & 0 & 1 & 0 & 0 & 1 & 1 & 0 & 1 & 0 & 0 & 1 & 0 & 0 \\
\hline 2 & 0 & 1 & 1 & 0 & 1 & 0 & 1 & 0 & 1 & 0 & 0 & 0 & 1 & 0 & 1 & 0 & 1 & 0 & 0 & 0 \\
\hline 3 & 0 & 0 & 1 & 0 & 1 & 0 & 1 & 1 & 1 & 1 & 0 & 0 & 1 & 0 & 1 & 0 & 1 & 0 & 0 & 0 \\
\hline 4 & 0 & 0 & 1 & 0 & 1 & 0 & 1 & 1 & & 1 & 0 & 1 & 0 & 0 & 1 & 0 & 0 & 1 & 0 & 0 \\
\hline 5 & 0 & 0 & 1 & 0 & 1 & 0 & 0 & 0 & 1 & 0 & 0 & 1 & 0 & 0 & 1 & 0 & 1 & 0 & 1 & 0 \\
\hline 6 & 0 & 0 & 1 & 0 & 1 & 0 & 1 & 1 & 1 & 0 & 0 & 1 & 0 & 0 & 1 & 0 & 1 & 0 & 1 & 0 \\
\hline 7 & 0 & 0 & 0 & 1 & 1 & 0 & 0 & 1 & 1 & 1 & 0 & 1 & 0 & 0 & 1 & 1 & 0 & 1 & 0 & 0 \\
\hline 8 & 0 & 1 & 0 & 0 & 1 & 0 & 0 & 1 & 0 & 0 & 0 & 1 & 1 & 0 & 1 & 0 & 1 & 0 & 1 & 0 \\
\hline 9 & 0 & 1 & 1 & 0 & 1 & 0 & 0 & 0 & 1 & 0 & 0 & 1 & 1 & 0 & 1 & 0 & 1 & 0 & 1 & 0 \\
\hline 10 & 1 & 0 & 0 & 0 & 1 & 0 & 1 & 0 & 1 & 0 & 0 & 0 & 1 & 0 & 0 & 1 & 1 & 0 & 0 & 0 \\
\hline
\end{tabular}

Цветом обозначены уникальные генотипь берёзы.

\section{Библиографический список}

1. Zienkiewicz E. Genome fingerprinting by simple sequence repeats (SSR)-anchored polymerase chain reaction amplification [Text] / E. Zienkiewicz, A. Rafalski, B. Labuda // Genomics. - № 20. - P. 176-183.

2. Microsatellite sequences: a new generation of molecular markers for forest genetics [Text] / F. Lefort, C. Echt, R. Streiff, G. G. Vendramin // Forest Genetics. - 1999. - № 6 (1). - P. 15-20.

3. Järvinen P. Nucleotide variation of birch (Betula L.) species: population structure and phylogenetic relationships [Text] : PhD diss. / P. Järvinen. - Joensuu, 2004. - 138 p.

4. Изучение генетической структуры популяций карельской березы в Республике Карелии с помощью микросателлитного анализа [Текст] / Л. В. Ветчинникова, А. Ф. Титов, Л. В. Топчиева, Н. Л. Рендаков // Проблемы объектов лесной науки: современное состояние и перспективы. - Воронеж, 2014. - С. 10-12.

5. Оценка генетического разнообразия популяций карельской березы в Карелии с помощью микросателлитных маркеров [Текст] / Л. В. Ветчинникова, А. Ф. Титов, Л. В. Топчиева, Н. Л. Рендаков // Экологическая генетика. - 2012. - Т. 10. - № 1. - С. 34-37.

6. Исаков И. Ю. Генотипирование селекционных форм лиственных древесных растений с использованием баз данных сиквенсов ДНК [Текст] / И. Ю. Исаков // Проблемы объектов лесной науки: современное состояние и перспективы. - Воронеж, 2014. - С. 42-43.

7. Population history, genetic variation and conservation status of the endangered birch species Betula nana $\mathrm{L}$. in Poland [Text] / K. A. Jadwiszczak, D. Drzymulska, A. Banaszek, P. Jadwiszczak // Silva Fennica. - 2012. - № 46 (4). P. 465-477.

8. Genetic diversity and genetic structure of adult and buried seed populations of Betula maximowicziana in mixed and post-fire stands [Text] / K. Uchiyama, S. Goto, Y. Tsuda, Y. Takahashi, Y. Ide // Forest Ecology and Management. - 2006. - № 237. - P. 119-126. 
9. Kulju K. K. M. Twenty-three microsatellite primer pairs for Betula pendula (Betulaceae) [Text] / K. K. M. Kulju, M. Pekkinen, S. Varvio // Molecular Ecology Notes. - 2004. - № 4. - P. 471-473.

10. Isolation and characterization of microsatellite markers in the tetraploid birch, Betula pubescens ssp. tortuosa [Text] / C. Truong, A. E. Palmé, F. Felber, Y. Naciri-Graven // Molecular Ecology Notes. - 2005. - № 5. - P. 96-98.

11. Isolation and characterization of 19 microsatellite markers in a tropical and warm subtropical birch, Betula alnoides Buch.-Ham. ex D. Don [Text] / J. J. Guo, J. Zeng, S. L. Zhou, Z. G. Zhao // Molecular Ecology Resources. 2008. - № 8 (4). - P. 895-897.

12. Gürcan K. Transferability of microsatellite markers in the Betulaceae [Text] / K. Gürcan, Sh. A. Mehlenbacher // J. Amer. Soc. Hort. Sci. - 2010. - № 135 (2). - P. 159-173.

13. Cross-species amplification of Betula pendula Roth simple sequence repeat markers in Alnus species [Text] / A. Zhuk, I. Veinberga, M. Daugavietis, D. Ruņǵis // Baltic Forestry. - 2008. - № 14 (2). - P. 116-121.

14. Исаков Ю. Н. Интеграционно-эпигенетическое происхождение карельской берёзы: гипотеза и факты [Текст] / Ю. Н. Исаков, Н. М. Соустова, И. Ю. Исаков // Структурные и функциональные отклонения от нормального роста и развития растений под воздействием факторов среды. - Петрозаводск, 2011. - С. 98-103.

15. Palmé A. Evolution history and chloroplast DNA variation in three plant genera: Betula, Corylus and Salix. The impact of post-glacial colonisation and hybridization [Text] : Comprehensive summaries of dokt. diss. / A. Palmé. Uppsala, 2003. $-59 \mathrm{p}$.

16. Linkage map of birch, Betula pendula Roth, based on microsatellites and amplified fragment length polymorphisms [Text] / M. Pekkinen, S. Varvio, K. K. M. Kulju, H. Kärkkäinen, S. Smolander, A. Viherä-Aarnio, V. Koski, M. J. Sillanpää // Genome. - 2005. - № 48. - P. 619-625.

17. Doyle J. J. A rapid DNA isolation procedure for small quantities of fresh leaf tissue [Text] / J. J. Doyle, J. L. Doyle // Phytochem Bull. - 1987. - № 19. - P. 11-15.

\section{References}

1. Zienkiewicz E. Genome fingerprinting by simple sequence repeats (SSR)-anchored polymerase chain reaction amplification / E. Zienkiewicz, A. Rafalski, B. Labuda // Genomics. - № 20. - P. 176-183.

2. Microsatellite sequences: a new generation of molecular markers for forest genetics / F. Lefort, C. Echt, R. Streiff, G. G. Vendramin // Forest Genetics. - 1999. - № 6 (1). - P. 15-20.

3. Järvinen P. Nucleotide variation of birch (Betula L.) species: population structure and phylogenetic relationships: PhD diss. / P. Järvinen. - Joensuu, 2004. - 138 p.

4. Izucheniye geneticheskoy struktury populyatsiy karelskoy berozy $\mathrm{v}$ Respublike Karelii s pomoshchyu mikrosatellitnogo analiza / L. V. Vetchinnikova, A. F. Titov, L. V. Topchiyeva, N. L. Rendakov // Problemy obyektov lesnoy nauki: sovremennoe sostoyanie i perspektivy. - Voronezh, 2014. - S. 10-12.

5. Otsenka geneticheskogo raznoobraziya populyatsiy karelskoy berezy $\mathrm{v}$ Karelii $\mathrm{s}$ pomoshchyu mikrosatellitnykh markerov / L. V. Vetchinnikova, A. F. Titov, L. V. Topchiyeva, N. L. Rendakov // Ekologicheskaya genetika. - 2012. - T. 10. - № 1. - S. 34-37.

6. Isakov I. Yu. Genotipirovanie selektsionnykh form listvennykh drevesnykh rasteniy s ispolzovaniem baz dannykh sikvensov DNK / I. Yu. Isakov // Problemy obyektov lesnoy nauki: sovremennoe sostoyanie i perspektivy.-Voronezh, 2014. - S. 42-43.

7. Population history, genetic variation and conservation status of the endangered birch species Betula nana $\mathrm{L}$. in Poland / K. A. Jadwiszczak, D. Drzymulska, A. Banaszek, P. Jadwiszczak // Silva Fennica. - 2012. - № 46 (4). P. 465-477.

8. Genetic diversity and genetic structure of adult and buried seed populations of Betula maximowicziana in mixed and post-fire stands / K. Uchiyama, S. Goto, Y. Tsuda, Y. Takahashi, Y. Ide // Forest Ecology and Management. 2006. - № 237. - P. 119-126. 
9. Kulju K. K. M. Twenty-three microsatellite primer pairs for Betula pendula (Betulaceae) / K. K. M. Kulju, M. Pekkinen, S. Varvio // Molecular Ecology Notes. - 2004. - № 4. - P. 471-473.

10. Isolation and characterization of microsatellite markers in the tetraploid birch, Betula pubescens ssp. tortuosa / C. Truong, A. E. Palmé, F. Felber, Y. Naciri-Graven // Molecular Ecology Notes. - 2005. - № 5. - P. 96-98.

11. Isolation and characterization of 19 microsatellite markers in a tropical and warm subtropical birch, Betula alnoides Buch.-Ham. ex D. Don / J. J. Guo, J. Zeng, S. L. Zhou, Z. G. Zhao // Molecular Ecology Resources. - 2008. № 8 (4). - P. 895-897.

12. Gürcan K. Transferability of microsatellite markers in the Betulaceae / K. Gürcan, Sh. A. Mehlenbacher // J. Amer. Soc. Hort. Sci. - 2010. - № 135 (2). - P. 159-173.

13. Cross-species amplification of Betula pendula Roth simple sequence repeat markers in Alnus species / A. Zhuk, I. Veinberga, M. Daugavietis, D. Runggis // Baltic Forestry. - 2008. - № 14 (2). - P. 116-121.

14. Isakov Yu. N. Integratsionno-epigeneticheskoye proiskhozhdeniye karelskoy berozy: gipoteza i fakty / Yu. N. Isakov, N. M. Soustova, I. Yu. Isakov // Strukturnye i funktsionalnye otkloneniya ot normalnogo rosta i razvitiya rasteniy pod vozdeystviyem faktorov sredy. - Petrozavodsk, 2011. - S. 98-103.

15. Palmé A. Evolution history and chloroplast DNA variation in three plant genera: Betula, Corylus and Salix. The impact of post-glacial colonisation and hybridisation: Comprehensive summaries of dokt. diss. / A. Palmé. Uppsala, 2003. - 59 p.

16. Linkage map of birch, Betula pendula Roth, based on microsatellites and amplified fragment length polymorphisms / M. Pekkinen, S. Varvio, K. K. M. Kulju, H. Kärkkäinen, S. Smolander, A. Viherä-Aarnio, V. Koski, M. J. Sillanpää // Genome. - 2005. - № 48. - P. 619-625.

17. Doyle J. J. A rapid DNA isolation procedure for small quantities of fresh leaf tissue / J. J. Doyle, J. L. Doyle // Phytochem Bull. - 1987. - № 19. - P. 11-15.

\section{Сведения об авторах}

Федулова Татьяна Петровна - доктор биологических наук, ведущий научный сотрудник лаборатории биотехнологии ФГБУ «Всероссийский научно-исследовательский институт лесной генетики, селекции и биотехнологии», 394043, г. Воронеж, ул. Ломоносова, д. 105, т.: +7 (473) 253-71-89, e-mail: biotechnologiya@ mail.ru

Исаков Юрий Николаевич - доктор биологических наук, ведущий научный сотрудник лаборатории экологической генетики ФГБУ «Всероссийский научно-исследовательский институт лесной генетики, селекции и биотехнологии», 394043, г. Воронеж, ул. Ломоносова, д. 105, т.: +7 (473) 253-71-89

Корчагин Олег Михайлович - директор ФГБУ «Всероссийский научно-исследовательский институт лесной генетики, селекции и биотехнологии», г. Воронеж, ул. Ломоносова, д. 105; кандидат биологических наук, доцент кафедры ботаники и физиологии растений ФГБОУ ВО «Воронежский государственный лесотехнический университет имени Г.Ф. Морозова», г. Воронеж, ул. Тимирязева, 8

Исаков Игорь Юрьевич - кандидат сельскохозяйственных наук, доцент кафедры лесных культур, селекции и лесомелиорации ФГБОУ ВО «Воронежский государственный лесотехнический университет имени Г.Ф. Морозова», г. Воронеж, ул. Тимирязева, 8, e-mail:isakov@ vmail.ru

Кондратьева Анна Михайловна - кандидат биологических наук, научный сотрудник ФГБУ «Всероссийский научно-исследовательский институт лесной генетики, селекции и биотехнологии», 394043, г. Воронеж, ул. Ломоносова, д. 105, т.: +7 (473) 253-71-89, e-mail: kondratyeva_anya@mail.ru

Ржевский Станислав Геннадъевич - младший научный сотрудник ФГБУ «Всероссийский научноисследовательский институт лесной генетики, селекции и биотехнологии», 394043, г. Воронеж, ул. Ломоносова, д. 105, т.: +7 (473) 253-71-89, e-mail: molecularbiotech@ mail.ru 


\section{Information about authors}

Fedulova Tatiana Petrovna - Doctor of biological Sciences, leading researcher of laboratory of biotechnology, FSBI "All-Russian research Institute of forest genetics, breeding and biotechnology", 394043, Voronezh, Lomonosov street, d. 105, t: +7 (473) 253-71-89, e-mail: biotechnologiya@mail.ru

Isakov Yuri Nikolaevich - Doctor of biological Sciences, leading researcher of laboratory of ecological genetics, FSBI "All-Russian research Institute of forest genetics, breeding and biotechnology", 394043, Voronezh, Lomonosov street, d. 105, t: +7 (473) 253-71-89

Korchagin Oleg Mikhailovich - Director of FSBI "All-Russian research Institute of forest genetics, breeding and biotechnology", Voronezh, Lomonosov street, d. 105, t: +7 (473) 253-71-89; Candidate of biological Sciences, Associate Professor of the Department of botany and plant physiology, "Voronezh State Forestry Engineering University named after G. F. Morozov", Voronezh, Timiryazev str., 8

Isakov Igor Yurievich - Candidate of agricultural Sciences, Associate Professor of forest crops, selection and forest reclamation, "Voronezh State Forestry Engineering University named after G. F. Morozov", Voronezh, Timiryazev str., 8 e-mail:isakov@ vmail.ru

Kondratieva Anna Mikhailovna - Candidate of biological Sciences, Researcher of the FSBI "All-Russian research Institute of forest genetics, breeding and biotechnology", 394043, Voronezh, Lomonosov street, d. 105, t: +7 (473) 253-71-89, e-mail: kondratyeva_anya@mail.ru

Rzhevskiy Stanislav Gennadyevich - Junior researcher of the FSBI "All-Russian research Institute of forest genetics, breeding and biotechnology", 394043, Voronezh, Lomonosov street, d. 105, t: +7 (473) 253-71-89, e-mail: molecularbiotech@mail.ru 